6. Talon.-Arch. de Med. et de Pharmacie militaires (1883). Quoted by Heerfordt. $\mathrm{A}-\mathrm{i}$

7. Burnett Swan.-On Affections of the Eye accompanying Mumps. International Jl. of the Med. Sciences, Vol. XCI, 1886, p. 86. (This is now the Amer. Jl. of Med. Sciences.)

8. Blanchard.-Bulletin Méd. 1899, p. 1091.

9. Baas.-Klin. Monatsbl., f. Augenheilk., 1886, p. 273.

10. Mandonnet.-Paralysie de l'accommodation et du voile du palais, consécutive aux oreillons. Ann. d'Ocul., 1903.

11. Dopter.-Gazette des Hôpitaux. No. 87, 1904.

\title{
TRANSLATION
}

\section{A CASE OF SUB-CHRONIC FEBRILE UVEO-PAROTID INFLAMMATION*}

BY

\section{Dr. E. Kuhlefelt}

IN the Ugeskrift for Laeger No. 16-17, 1909, Heerfordt gives an account of one case observed by Daireaux and Péchin, one by Collomb and three by himself of an affection which in many respects resembles epidemic parotitis. As these cases, however, show several important deviations from even atypical epidemic parotitis, Heerfordt considers that they should be relegated to a different group which he proposes to call "febris uveo-parotitis subchronica."

With one exception these cases occurred at times when there was no epidemic parotitis. All the patients were healthy and free from hereditary taint. The disease lasted from three to nine months, of which the prodromal stage occupied at the least some days, and at the most a few months. The symptoms of the prodromal stage resembled those which usually precede an attack of typhus (enteric ?). The accompanying fever was, as a rule, slight, and not subject to much change, but in some cases there were exacerbations which did not always completely coincide with the outbreak of localized changes. These changes, of which the uveitides, which always occurred, deserve special notice, occurred primarily in the parotid in some, and in the uvea in others. No other glandular changes were observed. (In a case which Schou published later, there was a simultaneous swelling of the lacrymal gland.) Though varying somewhat in degree the parotitis was in all cases of a mild

*Taken from the Finska Läkaresällskapets Handlingar, redigerade af DR. RICHARD Sievers. Band LVIII, May, 1916, pp. 867-870. 
type. In one case structures resembling papules were found on the iris. (In Schou's case there were nodular prominences on the iris.)

The complications observed by Heerfordt in epidemic parotitis were only pareses of cerebral nerves, joint affections and optic neuritis. While the last was only an exceptional complication in epidemic parotitis, it occurred in several of the cases described by Heerfordt. Pareses seemed also to be more frequent in febris uveoparotida than in parotitis epidemica. Besides the complications already mentioned, there was one case in which there were disturbances of sensibility and of reflexes and increased diuresis. As I have had occasion to observe one case of this unusual disease I give a short account of it:

Miss E. L., clerk, aged 21, from Helsingfors came to see me for the first time on August 20, 1915. History :-The father died of tuberculosis, but there were no other cases in the family. Lues could be excluded in both parents and patient. Parotitis epidemica as a child. In adolescence some affection of the fourth metacarpophalangeal joint of the right hand. Patient was not aware of having been in contact with anyone sickening for any illness. Since July, swelling and tenderness in each parotid region. Diminution of vision in the right eye August 15; August 18 last joint of left little finger, head and eyes painful. Feels tired. Has not noticed any symptoms of fever or of weakness or disturbance of taste or sensibility.

Status presens :-Delicate, thin, anæmic (hæmoglobin ca. 75 per cent). Acute laryngo-bronchitis, but no demonstrable changes suggestive of tuberculosis. Apices alike and clear (Prof. Talqvist). Urine free from sugar and albumen on repeated examinations. No symptoms indicative of sinusitis (no mucus or pus from maxillary or sphenoidal sinuses). Preauricular portion of each parotid somewhat swollen and tender. The right retro-maxillary portion nearly the size of an infant's hand, the left somewhat tender and uneven pigeon-egg sized; surrounding parts not swollen. Nothing abnormal in mouth or throat. Sublingual, submaxillary and lacrymal glands neither tender nor swollen. No tenderness in the region of the ovaries.

R.E. Conjunctiva oculi somewhat injected, small deposits on the lower part of Descemet's membrane, iris a little hyperæmic. Media clear, papilla and retina over a wide circumpapillary area grey, turbid and swollen; blood-vessels invisible at places; veins swollen and tortuous; numerous large and smaller hæmorrhages and grey patches in the inner and lower quadrant of the fundus. V. $=5 / 10$. L.E. normal condition. Last joint left little finger swollen and tender.

Tactile sensation normal everywhere; sensation of pain slightly blunted in places (left upper arm), otherwise normal; left patellar 
reflex not easily elicited, reflexes otherwise normal; no demonstrable pareses.

Treatment and Course :-August 20. Aspirin, sweating, atropin.

August 23. Pupil fairly well dilated, though irregularly; iris swollen; exudation in pupil. No details of fundus visible. V. $=$ fingers 1.1 metre. Admitted to hospital. Aspirin, sweating, inunction.

August 29. L.E. Pericorneal injection, some iris congestion.

September 1. L.E. free from irritation. Swelling and tenderness right great toe.

September 12. Left hospital.

September 17. Swelling of parotids, which had diminished lately, increased a little, particularly the right. Little finger well. Iritis passing off, details begin to show in fundus. V.=fingers at $1.5 \mathrm{M}$.

September 28. Right parotitis rather increased lately. Iritis gone. Papilla better seen, with four faint-grey, segregated large retinal vessels visible. $\mathrm{V}$. $=$ fingers at 2.5 metres. Atropin and inunction stopped. Collo-iodide and sweating.

October 8. Margins of papilla visible, surrounding retina light grey; in the macular region small grey patches and pigment ; inner and lower quadrant of fundus worm-shaped grey patch stretching from papilla far out to periphery, where it branches into two. V.= fingers at 4 metres. Great toe well.

October 18. Sweat cure discontinued. Iron.

October 28. Papilla pale, papillary vessels in the main visible, surrounding retina normal in appearance, in the macular area there remain only the pigment patches, the worm-shaped patch is white. $\mathrm{V}:=$ fingers at 5 metres. Swelling in parotid glands markedly reduced. General condition rather better. Collo-iodide discontinued. Arsenic.

The temperature has varied in the mornings between $36.2^{\circ}$ and $37.3^{\circ} \mathrm{C}$., and in the evenings between $36.3^{\circ}$ and $37.4^{\circ} \mathrm{C}$. There have been four definite rises of short duration, the maximum in the first being $37.7^{\circ} \mathrm{C}$., in the second $37.7^{\circ} \mathrm{C}$., in the third $37.5^{\circ} \mathrm{C}$, and in the fourth $37.9^{\circ} \mathrm{C}$. Possibly the first of these was connected with the iritis in the left eye, and the second with an exacerbation of the right-sided parotitis. In the third and fourth, there was neither exacerbation of localized symptoms nor the occurrence of anything fresh.

The diuresis while in hospital was 1,100 to 1,950 c.cm. per 24 hours. The case occurred at a time when there were in the patient's neighbourhood only isolated cases of epidemic parotitis. (In Helsingfors three in June, four in July and not a single case in August were notified.) So far as is known, too, the disease was not transmitted to anyone else.

G. A. BERRY. 